\title{
Differential classification of dementia
}

\author{
E. Mohr ${ }^{1}$, P. Brouwers ${ }^{2}$, J.J. Claus ${ }^{3}$, S.E. Purdon ${ }^{1}$, M. Gagnon ${ }^{1}$ and T.N. \\ Chase $^{3}$ \\ ${ }^{1}$ SCO Hospitals, Elisabeth Bruyere Health Center, Rm 298-20, 75 Bruyere St, Ottawa, Ontario, \\ Canada K1N 5 C8
}

Correspondence to: E. Mohr at above address

\begin{abstract}
In the absence of biological markers, dementia classification remains complex both in terms of characterization as well as early detection of the presence or absence of dementing symptoms, particularly in diseases with possible secondary dementia. An empirical, statistical approach using neuropsychological measures was therefore developed to distinguish demented from nondemented patients and to identify differential patterns of cognitive dysfunction in neurodegenerative disease. Age-scaled neurobehavioral test results (Wechsler Adult Intelligence Scale-Revised and Wechsler Memory Scale) from Alzheimer's (AD) and Huntington's (HD) patients, matched for intellectual disability, as well as normal controls were used to derive a classification formula. Stepwise discriminant analysis accurately $(99 \%$ correct) distinguished controls from demented patients, and separated the two patient groups (79\% correct). Variables discriminating between HD and AD patient groups consisted of complex psychomotor tasks, visuospatial function, attention and memory. The reliability of the classification formula was demonstrated with a new, independent sample of $\mathrm{AD}$ and $\mathrm{HD}$ patients which yielded virtually identical results (classification accuracy for dementia: 96\%; AD versus HD: $78 \%$ ). To validate the formula, the discriminant function was applied to Parkinson's (PD) patients, $38 \%$ of whom were classified as demented. The validity of the classification was demonstrated by significant PD subgroup differences on measures of dementia not included in the discriminant function. Moreover, a majority of demented PD patients (65\%) were classified as having an HD-like pattern of cognitive deficits, in line with previous reports of the subcortical nature of PD dementia. This approach may thus be useful in classifying presence or absence of dementia and in discriminating between dementia subtypes in cases of secondary or coincidental dementia.
\end{abstract}

Keywords: Cortical and subcortical dementia - Dementia classification - Discriminant analysis - Neuropsychological measures

\section{INTRODUCTION}

A large number of medical disorders are associated with dementia, either as a primary presenting symptom, as is the case in Alzheimer's disease (AD), or as a secondary or coincidental aspect of illness, as in Parkinson's disease (PD; e.g. Mohr et al., 1990b; Levin et al., 1991) or HIV infection (e.g. Navia et al., 1986; Price et al., 1988). The absence of confirmed, definitive biological markers for dementia in vivo (notwithstanding other diagnostic criteria for the respective illnesses associated with non-Alzheimer-type dementias) necessitates a clinical approach, including the use of neuropsychological and behavioral measures, such as mental status examinations, the revised Diagnostic and Statistical Manual of Mental Disorders (DSM-III-R) criteria for dementia (American Psychiatric Association, 1987) and the National Institute of Neurological and Communicative Disorders and Stroke - Alzheimer's Disease and Related Disorders Association (NINCDS-ADRDA) criteria (McKhann et al., 1984). While reasonably accurate in the context of $\mathrm{AD}$, the use of these criteria by themselves is more

(C) 1995 Rapid Communications of Oxford Ltd difficult when applied to other dementing disorders. In the latter context, only a limited number of patients may evidence actual dementia and even those may not necessarily score in the impaired range on mental status exams and/or fulfil all of the other indices of dementia stipulated by DSM-III-R and/or NINCDS-ADRDA criteria (Cummings, 1990). The application of established benchmarks for dementia based on AD or the use of simple cut-off scores on mental status exams may therefore be insufficient for the diagnosis of secondary or coincidental dementia.

Considerable research attention has focused on differential classification of primary dementias (e.g. Cummings, 1986; Goodin and Aminoff, 1986; Salmon et al, 1989), and while such distinctions remain controversial, they may have important consequences for the understanding of disease processes (Mohr et al., 1990a; Hodges et al., 1990), both in primary as well as secondary dementias. Current differential classification schemas are most often based on characteristic transmitter system alterations 
E. MOHR ET AL.

TABLE I. Sample Characteristics [mean \pm S.E.M. (range)]

\begin{tabular}{lccccr}
\hline & $n$ & Age (years) & $\operatorname{Sex}(\mathrm{M} / \mathrm{F})$ & Education (years) & \multicolumn{1}{c}{ Full Scale IQ } \\
\hline Criterion sample & & & & & \\
$\quad$ Alzheimer's & 19 & $64 \pm 1.8(53-80)$ & $11 / 8$ & $16 \pm 1(12-20)$ & $90 \pm 2.3(77-109)$ \\
$\quad$ Huntington's & 19 & $44 \pm 3.1(25-76)$ & $11 / 8$ & $14 \pm 1(11-20)$ & $90 \pm 2.6(72-111)$ \\
$\quad$ Normal controls & 29 & $41 \pm 3.0(19-71)$ & $11 / 18$ & $15 \pm 0.4(12-20)$ & $118 \pm 9.8(94-133)$ \\
$\quad$ Reliability sample & & & & & \\
$\quad$ Alzheimer's & 10 & $65 \pm 1.8(56-74)$ & $5 / 5$ & $11 \pm 0.7(7-14)$ & $85 \pm 6.9(56-107)$ \\
$\quad$ Huntington's & 18 & $48 \pm 3.2(23-66)$ & $9 / 9$ & $11 \pm 0.7(7-17)$ & $83 \pm 2.4(72-105)$ \\
$\quad \begin{array}{l}\text { Validation sample } \\
\quad \text { Parkinson's }\end{array}$ & 45 & $61 \pm 2.0(39-75)$ & $35 / 10$ & $16 \pm 1(12-20)$ & $105 \pm 2.1(81-131)$ \\
\hline
\end{tabular}

(Perry, 1986; Mann and Yates, 1986; Carlsson, 1987; Cummings, 1988), neuropathological features (Jellinger, 1987) or clinical profiles (Cummings and Benson, 1984; Huber and Paulson, 1985). The latter typically rely on neurobehavioral patterns and distinguish dementias on neuropsychological grounds (e.g. Cummings, 1986). One of the more widely utilized clinical models separates dementia into cortical or subcortical subtypes (Albert et al., 1974; Cummings and Benson, 1984; Huber et al., 1986; Cummings, 1986, 1988; Brown and Marsden, 1988). The cortical variant has been associated predominantly with aphasia, agnosia, apraxia, acalculia and marked memory problems (e.g. Brown and Marsden, 1988). Subcortical dementia on the other hand has been linked to cognitive and memory impairment, with poor problem solving produced by slowness, impaired planning and application of strategies, and poor memory marked by difficulty retrieving learned material (e.g. Brown and Marsden, 1988; Heindel et al., 1989, 1990). AD is generally considered to be the principal example of a cortical dementia, while subcortical dementia has been associated with Huntington's disease (HD), PD and progressive supranuclear palsy (Albert et al., 1974; Cummings and Benson, 1984; Huber and Paulson, 1985; Cummings, 1986, 1988; Pillon et al., 1991).

Separation of dementia into two broad clinical categories, namely cortical and subcortical dementia, may well be useful. However, factors like severity of dementia, age-related performance differences and considerable performance heterogeneity in individual patients confound possible contrasts. In an attempt to develop a more rigorous approach to distinguishing demented patients from non-demented individuals and to define more precisely differential patterns of cognitive impairment in the context of secondary or coincidental dementia, the following study was undertaken.

\section{METHODS}

Nineteen patients with a clinical diagnosis of probable AD, based on DSM-III-R (American Psychiatric Association, 1987) and NINCDS-ADRDA criteria (McKhann et al., 1984) and 19 patients with HD, diagnosed on the basis of positive family history, evidence of striatal atrophy on computed tomography (CT) scan and neurological examination served as study subjects for the criterion sample (see Table I for subject characteristics). Both patient groups were matched for overall level of intellectual functioning on the basis of their Full Scale IQ (WAIS-R; Wechsler, 1981) and education. All patients had been free of centrally active medications for at least 4 weeks prior to admission to the study and were seen for diagnostic purposes in the out-patient clinic of the Experimental Therapeutics Branch, NINDS at the National Institutes of Health in Bethesda, Maryland, USA. Twenty-nine neurologically normal subjects, matched to the two patient groups for education, served as criterion sample controls (Table I). None had received centrally active medication for at least 4 weeks prior to study entry.

A separate reliability sample (Table I) of 10 patients with probable $\mathrm{AD}$ and 18 individuals with HD, diagnosed by the same criteria as the NIH sample, was tested in the Memory Loss Clinic of the Neurodegenerative Disorders Branch, Institute of Mental Health Research in Ottawa, Ontario, Canada. The reliability sample was unselected for IQ levels. As in the original sample, all patients had been free of centrally active medications for at least 4 weeks prior to testing.

A validation sample of 45 patients with PD, matched to the original two patient groups and controls for education, unselected for cognitive or motor status, also participated (Table I). Thirteen patients were in stage I of the modified Hoehn and Yahr scale (Fahn et al., 1987), seven were in stage II, 18 in 
TABLE II. Classification formula by which patients can be classified as normal or demented, and if demented, as more Alzheimer- or Huntington-like. DI is digit span, BD is block design, OA is object assembly (WAIS-R subtests, age-scaled scores), SCVI is age-scaled visual reproduction score (WMS) andMQ is Memory Quotient (WMS). Cases are classified according to the highest posterior probability

Classification scores
$Y_{1}=(0.13692 \times \mathrm{DI})+(-0.09851 \times \mathrm{BD})+(0.69456 \times$
$\mathrm{OA})+(-0.71476 \times \mathrm{SCV})+(0.88242 \times \mathrm{MQ})-56.09480$
$Y_{2}=(0.53637 \times \mathrm{DI})+(-0.55816 \times \mathrm{BD})+(0.70889 \times$
$\mathrm{OA})+(-0.21171 \times \mathrm{SCVI})+(0.50142 \times \mathrm{MQ})-23.16936$
$Y_{3}=(0.12700 \times \mathrm{DI})+(0.05536 \times \mathrm{BD})+(0.28611 \times$
$\mathrm{OA})+(-0.64365 \times \mathrm{SCVI})+(0.61651 \times \mathrm{MQ})-26.60475$

Posterior probabilities

$$
\begin{gathered}
\mathrm{PP}_{\text {Normal }}=\frac{\mathrm{e}^{Y_{1}}}{\mathrm{e}^{Y_{1}}+\mathrm{e}^{Y_{2}}+\mathrm{e}^{y_{3}}} \\
\mathrm{PP}_{\text {Alzheimer's }}=\frac{\mathrm{e}^{Y_{2}}}{\mathrm{e}^{Y_{1}}+\mathrm{e}^{Y_{2}}+\mathrm{e}^{Y_{3}}} \\
\mathrm{PP}_{\text {Huntington's }}=\frac{\mathrm{e}^{Y_{3}}}{\mathrm{e}^{Y_{1}}+\mathrm{e}^{Y_{2}}+\mathrm{e}^{Y_{3}}}
\end{gathered}
$$

TABLE III. Classification matrix results

\begin{tabular}{lccc}
\hline & \multicolumn{3}{c}{ Classified as: } \\
\cline { 2 - 4 } & AD-like & HD-like & Normal-like \\
\hline Criterion sample & & & \\
Alzheimer's & $16(84 \%)$ & $3(16 \%)$ & $0(0 \%)$ \\
Huntington's & $5(26 \%)$ & $14(74 \%)$ & $0(0 \%)$ \\
Normal controls & $0(0 \%)$ & $1(3 \%)$ & $28(97 \%)$ \\
Reliability sample & & & \\
$\quad$ Alzheimer's & $7(70 \%)$ & $3(30 \%)$ & $0(0 \%)$ \\
Huntington's & $3(17 \%)$ & $14(78 \%)$ & $1(6 \%)$ \\
Validation sample & & & \\
$\quad$ Parkinson's & $6(13 \%)$ & $11(24 \%)$ & $28(62 \%)$ \\
\hline
\end{tabular}

stage III, four in stage IV and three in stage V while unmedicated. Patients evidenced a mean duration of parkinsonian symptoms of $9 \pm 0.7$ years, with a range of 1-21 years. None received centrally active medications (including anticholinergics or deprenyl) for at least 4 weeks prior to neuropsychological testing, except for levodopa, which was temporarily discontinued approximately $3 \mathrm{~h}$ before testing. Immediately prior to testing, a neurologist assessed patients' motor function; when an individual was deemed "off", testing proceeded. All study participants provided informed consent after full disclosure of the potential risks and benefits of the study.
Neuropsychological function was assessed with tests for which reliable age-scaled norms are available over the range of ages studied here (19-80 years). This was deemed necessary since the dementing disorders under investigation are differentially prevalent as a function of age. The Wechsler Adult Intelligence Scale-Revised (WAIS-R; Wechsler, 1981) with agescaled subtests and the Wechsler Memory Scale (WMS; Wechsler and Stone, 1945) with age-scaled subtests (Osborne and Davis, 1978) fulfilled these criteria. Mood state was assessed in Parkinson's patients only, due to the relatively greater difficulty of reliably assessing this sphere in the other patient groups; the inventory used was the Beck Depression Inventory (Beck et al., 1961).

Data from the criterion sample of $\mathrm{AD}$ and $\mathrm{HD}$ patients and normal controls were analyzed with a stepwise linear discriminant analysis (Dixon et al., 1990), which was used to develop a formula by which patients could be classified as normal or demented, and if demented, as more Alzheimer- or Huntington-like. The contrast in the stepwise linear discriminant analysis was set to optimize differences between $\mathrm{AD}$ and $\mathrm{HD}$ patients. Probabilities were set to match sample size. The derived formula (Table II) was then applied to a reliability sample of new, unselected $\mathrm{AD}$ and $\mathrm{HD}$ patients. The formula was also used to classify patients with Parkinson's disease (validation sample) as non-demented or demented, and to subclassify those categorized as demented as Alzheimer- or Huntington-like. Additional subgroup comparisons on alternative neuropsychological measures were made using ANOVA and post-hoc planned $t$-tests to test the validity of the classification. (Results of the same procedure applied to HIV-infected, symptomatic adult patients are reported elsewhere.)

\section{RESULTS}

Neuropsychological test scores of the criterion sample of Alzheimer, Huntington and control subjects yielded a highly significant group separation (stepwise linear discriminant analysis), with an overall classification accuracy of $87 \%(58 / 67 ; p<0.001$; Table III). Twenty-eight of 29 controls (97\%), 16 of 19 Alzheimer's patients (84\%) and 14 of 19 Huntington's patients $(74 \%)$ were correctly classified. Discrimination between demented and non-demented subjects was virtually perfect $(99 \%)$. Within the demented groups, discrimination between Alzheimerand Huntington-type dementias was also highly accurate $(79 \%$ correct, $30 / 38 ; p<0.001)$.

Variables maximally separating the groups were 


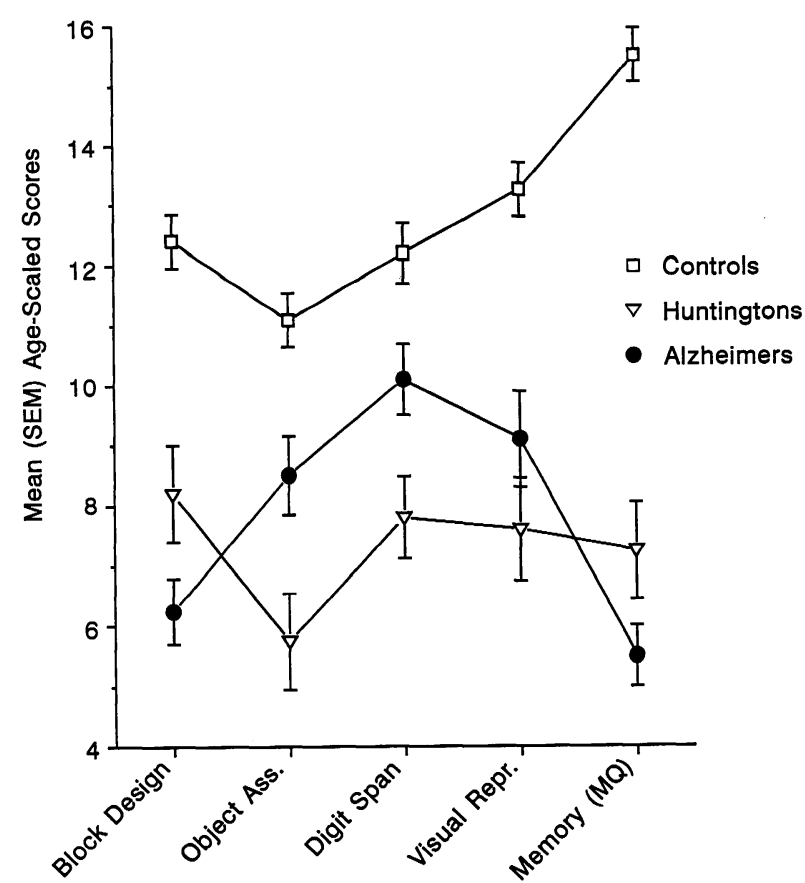

FIG. 1. Discrimination patterns of those variables identified as maximally separating Alzheimer's, Huntington's and control subjects.

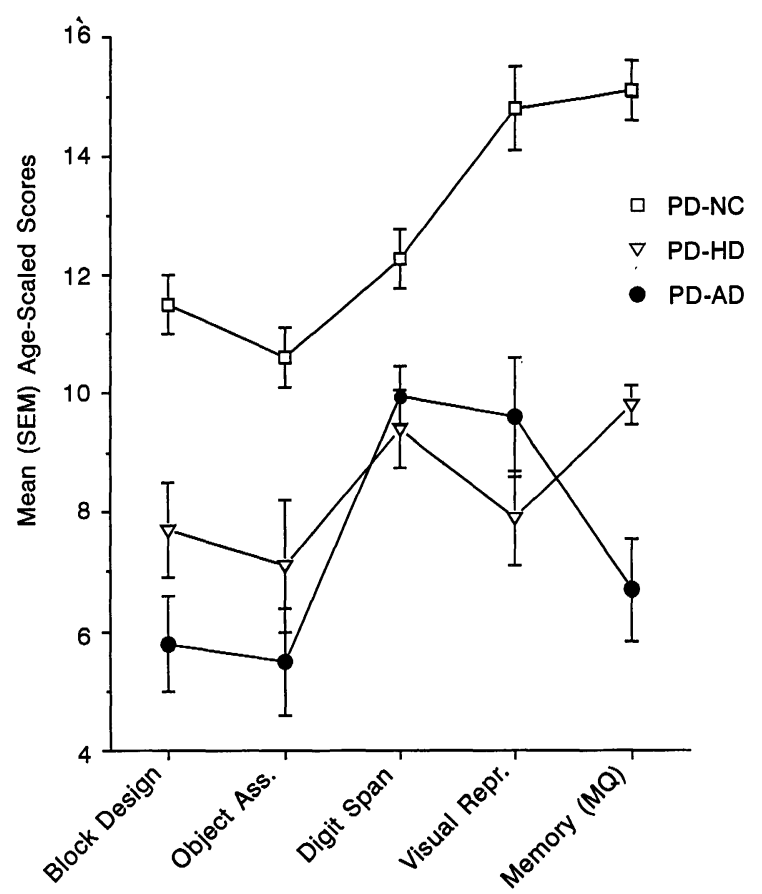

FIG. 2. Comparison of three Parkinson's subgroups identified with the discriminant formula developed from the criterion sample.

Block Design, Object Assembly, and Digit Span (WAIS-R subtests), as well as Memory Quotient
(WMS) and Visual Reproduction (WMS subtest). AD patients were relatively most impaired on visuospatial manipulation of patterns (Block Design) and global memory function (MQ), whereas those with HD tended to perform worse on visuospatial integration (Object Assembly) and reproduction (Visual Reproduction) and on attention (Digit Span; Fig. 1).

A reliability check with a different, independently obtained heterogeneous sample of AD and HD patients using the classification formula derived from the criterion sample resulted in an overall correct patient classification rate of $75 \%(21 / 28$; Table III). Twenty-seven of 28 patients $(96 \%)$ were correctly classified as demented. Within the group classified as demented, discrimination between AD- and HD-type dementia was also accurate $(78 \%, 21 / 27 ; p<0.01)$.

The discriminant function derived from the neuropsychological test scores of the criterion sample of Alzheimer's, Huntington's and control subjects was then applied to patients with PD for validation. Twenty-eight (62\%) were classified as normal and 17 $(38 \%)$ as demented (Table III). Dementia classifications using a standard mental status examination [Mattis Dementia Rating Scale (DRS); Mattis, 1976] were compared to the classification obtained with the stepwise linear discriminant function. Concordance rates of the two methods of dementia classification, stepwise linear discriminant analysis and DRS using a cut-off of 137 , averaged $78 \%$ in the PD patients. Seventy-seven per cent of patients classified as demented with the matrix were also classified as demented with the DRS; $79 \%$ of patients classified as normal with the matrix were also classified as normal with the DRS.

Of the 17 PD patients classified as demented, 11 $(65 \%)$ evidenced a Huntington-like or subcortical pattern of deficits, while six $(35 \%)$ demonstrated an Alzheimer-like or cortical dementia profile according to the classification formula (Table III; Fig. 2). The distribution of the PD patients within the "demented" categories was compared with the distribution of the criterion sample of Alzheimer's and Huntington's patients. The contrast of Parkinson's and Alzheimer's patients yielded significant differences between the two groups $\left(\chi^{2}=8.07 ; p<0.005\right)$. The contrast between Parkinson's and Huntington's patients in turn failed to reveal significant differences $\left(\chi^{2}=0.67 ; p>0.4\right)$.

Analysis of global intelligence quotients (WAIS-R Verbal and Performance IQ; VIQ; PIQ), which were not used in the stepwise linear discriminant function, indicated no significant differences between the Parkinson's subgroups for the VIQ-PIQ difference (mean $15 \pm 2.1$ ); this discrepancy was however signifi-

26 Behavioural Neurology . Vol 8 . 1995 
cantly different from zero $(p<0.001)$ and correlated significantly with Hoehn and Yahr scores $(r=0.4$; $p<0.01$ ). In contrast, the memory deficit (Memory Quotient - VIQ) was significantly larger for those PD patients classified as demented $(-8.0 \pm 5.1$ for AD-like and $-9.0 \pm 3.7$ for HD-like Parkinson's patients) compared to the normal-like Parkinson's group $(+8.0 \pm 1.9 ; p<0.01)$. Mean DRS scores were also significantly different between the three subgroups $(127 \pm 4.9,136 \pm 1.5$ and $141 \pm 0.6$ for the Alzheimer-, Huntington- and normal-like Parkinson's patients respectively, $p<0.001$ ).

Additional analyses contrasting Parkinson's patients classified as normal with those classified as HD- or AD-like on demographic and disease-related variables indicated that the Alzheimer-like PD patients suffered significantly longer (mean \pm S.E.M. $13.3 \pm 1.7$ years) from the disease than normal-like PD patients $(8.3 \pm 1.0, p<0.05)$, while Huntingtonlike PD patients did not differ significantly from either of the other two groups $(9.2 \pm 1.1$ years $)$. Duration of symptoms correlated significantly with motor.status, as assessed with the Hoehn and Yahr scale for all three groups as a whole $(r=0.6$, $p<0.01)$. There were no differences between Parkinson's subgroups in terms of mean age at onset of disease or mean age at which patients were evaluated. Depression scores (assessed with the Beck Depression Inventory) were highest in those classified as HD-like $(16.8 \pm 2.9)$ compared to AD-like (8.0 \pm 0.1 , $p<0.05)$ and normal-like Parkinson's patients $(9.1 \pm 1.1, p<0.01)$. Depression scores did not correlate with level of functioning on any of the variables in the discriminant equation (range of $r-0.23$ to + 0.21).

\section{DISCUSSION}

A statistical method to reliably identify and discriminate demented from non-demented patients with a high degree of accuracy ( $>96 \%$ correct) was developed. In addition, further classification of demented patients into those with cortical or subcortical dementia patterns was established. Since entry criteria stipulated equivalence of intellectual deterioration between Alzheimer's and Huntington's patients in the criterion sample, observed differences could not have been based primarily on differences in overall cognitive status. The reliability of the formula was shown by the similarity of results obtained in a new, independent sample of $\mathrm{AD}$ and HD patients.

Furthermore, the differences seen between cortical and subcortical dementia patterns are consistent with previously established clinical profiles, supporting the validity of the formula. The variables which optimally discriminated between $\mathrm{AD}$ and $\mathrm{HD}$ patients may reflect maximal functional involvement of different brain areas. Comparatively low scores on Block Design and Memory Quotient, measuring global memory function and visuospatial pattern manipulation, might be indicative of the well-documented parieto-temporal involvement, which has been associated with cortical (Alzheimer-like) dementia (e.g. Martin et al., 1986; Chase et al., 1987; Kramer et al., 1988; Mohr et al., 1991b; Pillon et al., 1991). Low scores on Object Assembly, Visual Reproduction and Digit Span, tests of visuospatial integration and reproduction and concentration/attention, on the other hand could represent a pattern of more frontal involvement, reflective perhaps of the putative disconnection between striatal-frontal structures, which has been associated with subcortical (Huntington-like) dementia (e.g. Brouwers et al., 1984; Mohr et al., 1991a; Pillon et al., 1991). Clearly, performance differences may well reflect differential cortical pathology, subcortical pathology, cortical disconnection or a combination thereof. Nevertheless, the ability to classify patients on the basis of their neurobehavioral performance with the method used here supports the idea that separating dementia along neurobehavioral lines may well be useful.

Of even greater practical importance may be differential dementia classification in the context of secondary or coincidental dementia. Current classification schema (mental status cut-off scores or application of criteria designed principally for Alzheimer-like dementia, e.g. NINCDS/ADRDA) may be inadequate in this context, and do not allow for further subclassification. Estimates of the incidence of dementia in Parkinson's patients vary, but currently available evidence suggests approximately $20-40 \%$ of patients are affected (e.g. Brown and Marsden, 1984; Ebmeier et al., 1990, 1991; Mayeux et al., 1990, 1992). Results of the current study (38\% demented) approximate the upper range of previous estimates, reflecting perhaps potentially greater accuracy of the classification method proposed here, particularly in the context of mild, early dementia. Subsequent work will need to examine the biological correlates of this classification schema, with particular emphasis on evaluating the potentially greater incidence of "false positives".

The concordance rates between dementia classification based on cut-off scores on a mental status examination (DRS) and classification with stepwise linear discrimination were nearly $80 \%$. Clearly, the more advanced the dementia, the easier the classification; difficulties arose with mild cases, which did not over- 
lap in terms of being classified as demented by both methods. Misclassification can have serious consequences, whether the error is a false negative or a false positive. Therefore, the use of a classification method which utilizes data multidimensionally and is maximized for differentiation may well be a useful addition in this context. Moreover, the ability to further differentiate between demented Parkinson's patients in terms of Alzheimer- versus Huntingtonlike dementia may be useful for subsequent treatment strategies, as differential transmitter involvement and potentially distinct pathogenetic cascades may be involved.

In the present study, when differentiating demented PD patients as Alzheimer-like or Huntington-like, the preponderance $(65 \%)$ of a Huntington-like dementia pattern is in agreement with previous observations, thus further validating our technique. It would appear that a majority of demented PD patients share certain features of the Huntington's subcortical deficit pattern, presumably associated with impairments in striatal-frontal connectivity, consistent with the frequent reports of "frontal" deficits in both disorders (e.g. Taylor et al., 1986; Brown and Marsden, 1988; Mohr et al., 1989; Massman et al., 1990; Pillon et al., 1991).

Thè validity of this approach was also documented by the contrast of summary measures not used in the discriminant profile. No significant differences were ascertainable between the three Parkinson's subgroups for the difference score between verbal and performance IQ. The performance IQ is in part dependent on motor speed and accuracy, while verbal IQ is largely independent of these parameters. As one would expect, the VIQ-PIQ score was significantly different from zero for all three groups, clearly reflecting Parkinsonian motor slowing, and correlated significantly with motor status (Hoehn and Yahr score). Further, the absence of significant differences in this measure between the three Parkinson's subgroups indicated that observed cognitive differences could not be attributed to differential motor function. When relative memory impairment was evaluated (Memory Quotient-Verbal IQ), both demented groups (AD- and HD-like PD patients) showed significantly greater impairment than normal-like Parkinson's patients. This confirms with an extraneous measure (not used in the discriminant analysis) that a memory deficit is significantly associated with being classified as demented in these Parkinson's patients.

Clearly, dementia is a heterogeneous process. Evidence presented here suggests that it is possible to reliably classify patients suffering from disorders associated with coincidental or secondary dementia as demented or non-demented. In addition, our method allows for further subclassification of patients, without confounding results by disease severity or age effects. Accordingly, two major advantages over traditionally used approaches emerge: (1) utilization of empirical rather than subjective clinical criteria, combined with a more comprehensive assessment than available with brief mental status exams; and (2) in addition to dementia classification (presence versus absence), this approach allows for further distinction between dementia subtypes. Confirmation of a high level of classification accuracy with a new, independent sample of patients attests to the practical utility of this approach. Added precision in classifying patients suffering from secondary or coincidental dementia and further diagnosis in terms of subtypes of dementia could allow for more precise treatment decisions, as new options unfold. In the absence of definitive biological markers, this type of neurobehavioral approach may well enhance diagnostic precision.

\section{Acknowledgements}

The authors wish to thank Margaret Sampson and Kathleen Hildebrand for their help in preparing this manuscript.

\section{REFERENCES}

Albert ML, Feldman RG and Willis AL (1974) The "subcortical dementia" of progressive subnuclear palsy. Journal of Neurology, Neurosurgery and Psychiatry, 37, 121130.

American Psychiatric Association (1987) Diagnostic and Statistical Manual of Mental Disorders, 3rd edn, revised. APA, Washington, DC.

Beck AT, Ward CH, Mendelson M, Mock J and Erbaugh J (1961) An inventory for measuring depression. Archives of General Psychiatry, 4, 561-571.

Brouwers P, Cox CS, Martin A, Chase TN and Fedio P (1984) Differential perceptual-spatial impairment in Huntington's and Alzheimer's dementias. Archives of Neurology, 41, 1073-1076.

Brown RG and Marsden CD (1984) How common is dementia in Parkinson's disease? Lancet, 2, 1262-1265.

Brown RG and Marsden CD (1988) Subcortical dementia: the neuropsychological evidence. Neuroscience, 25, 363387.

Carlsson A (1987) Brain neurotransmitters in aging and dementia: similar changes across diagnostic dementia groups. Gerontology, 33, 159-167.

Chase TN, Burrows GH and Mohr E (1987) Cortical glucose utilization patterns in primary degenerative dementias of the anterior and posterior type. Archives of Gerontology and Geriatrics, 6, 289-297.

Cummings JL (1986) Subcortical dementia: neuropsychology, neuropsychiatry, and pathology. British Journal of Psychiatry, 149, 682-697. 
Cummings JL (1988) The dementias of Parkinson's disease: prevalence, characteristics, neurobiology, and comparison with dementia of the Alzheimer's type. European Neurology, 28 (Suppl 1), 15-23.

Cummings JL (Ed.) (1990) Subcortical Dementia, pp. 3-16. Oxford University Press, New York.

Cummings JL and Benson DF (1984) Subcortical dementia: review of an emerging concept. Archives of Neurology, 41, 874-879.

Dixon WJ, Brown MB, Enselman L and Jennrich RI (1990) BMDP Statistical Software. University of California, Los Angeles.

Ebmeier KP, Calder SA, Crawford JR, Stewart L, Besson JAO and Mutch WJ (1990) Clinical features predicting dementia in idiopathic Parkinson's disease: a follow-up study. Neurology, 40, 1222-1224.

Ebmeier KP, Calder SA, Crawford JR, Stewart L, Cochrane RHB and Besson JAO (1991) Dementia in idiopathic Parkinson's disease: prevalence and relationship with symptoms and signs of Parkinsonism. Psychological Medicine, 21, 69-76.

Fahn S, Marsden CD, Calne DB and Goldstein M (1987) Recent Developments in Parkinson's Disease. Macmillan Health Care Information, New Jersey.

Goodin DS and Aminoff MJ (1986) Electrophysiological differences between subtypes of dementia. Brain, 109, 1103-1113.

Heindel WC, Salmon DP, Shults CW, Walicke PA and Butters N (1989) Neuropsychological evidence for multiple implicit memory systems: a comparison of Alzheimer's, Huntington's, and Parkinson's disease patients. Journal of Neuroscience, 9, 582-587.

Heindel WC, Salmon DP and Butters N (1990) Pictorial priming and cued recall in Alzheimer's and Huntington's disease. Brain and Cognition, 13, 282-295.

Hodges JR, Salmon DP and Butters N (1990) Differential impairment of semantic and episodic memory in Alzheimer's and Huntington's diseases: a controlled prospective study. Journal of Neurology, Neurosurgery and Psychiatry, 53, 1089-1095.

Huber SJ and Paulson GW (1985) The concept of subcortical dementia. American Journal of Psychiatry, 142, 13121317.

Huber SJ, Shuttleworth EC, Paulson GW, Bellchambers MJG and Clapp LE (1986) Cortical vs. subcortical dementia - neuropsychological differences. Archives of Neurology, 43, 392-394.

Jellinger K (1987) Neuropsychological substrates of Alzheimer's disease and Parkinson's disease. Journal of Neural Transmission, 24, 109-129.

Kramer JH, Delis DC, Blusewicz MJ, Brandt J, Ober BA and Strauss M (1988) Verbal memory errors in Alzheimer's and Huntington's dementias. Developmental Neuropsychology, 4, 1-5.

Levin BE, Llabre MM, Reisman S, Weiner WJ, SanchezRamos J, Singer C and Brown MC (1991) Visuospatial impairment in Parkinson's disease. Neurology, 41, 365369.

Mann DMA and Yates PO (1986) Neurotransmitter deficits in Alzheimer's disease and in other dementing disorders. Human Neurobiology, 5, 147-158.

Martin A, Brouwers P, Lalonde F, Cox C, Teleska P, Fedio P, Foster NL and Chase TN (1986) Towards a behavioral typology of Alzheimer's patients. Journal of Clinical and Experimental Neuropsychology, 8, 594 610.

Massman PJ, Delis DC, Butters N, Levin BE and Salmon DP (1990) Are all subcortical dementias alike?: verbal learning and memory in Parkinson's and Huntington's disease patients. Journal of Clinical and Experimental Neuropsychology, 12(5), 729-744.

Mattis S (1976) In: Geriatric Psychiatry (Eds L Bellack and TB Karasu), pp. 77-121. Grune and Stratton, New York.

Mayeux R, Chen J, Mirabello E, Marder K, Bell K, Dooneief G, Cote L and Stern Y (1990) An estimate of the incidence of dementia in idiopathic Parkinson's disease. Neurology, 40, 1513-1517.

Mayeux R, Denaro J, Hemenegildo N, Marder K, Tang M-X, Cote LJ and Stern Y (1992) A population-based investigation of Parkinson's disease with and without dementia: relationship to age and gender. Archives of Neurology, 49, 492-497.

McKhann G, Drachman D, Folstein M, Katzman R, Price D and Stadlan EM (1984) Clinical diagnosis of Alzheimer's disease: report of the NINCDS-ADRDA working group under the auspices of Department of Health and Human Services Task Force on Alzheimer's Disease. Neurology, 34, 939-944.

Mohr E, Fabbrini G, Williams J, Schlegel J, Cox C, Fedio $P$ and Chase TN (1989) Dopamine and memory function in Parkinson's disease. Movement Disorders, 4, 113-120.

Mohr E, Carter C and Wallin A (1990a) Group Report 2: Neurochemical substrates of human aging and dementia. Pharmacopsychiatry, 23 (Suppl.), 53-56.

Mohr E, Litvan I, Williams J, Fedio P and Chase TN (1990b) Selective deficits in Alzheimer and Parkinsonian dementia: visuospatial function. Canadian Journal of Neurological Sciences, 17, 292-297.

Mohr E, Brouwers P, Claus JJ, Mann UM, Gearing M, Fedio $P$ and Chase TN (1991a) Visuospatial cognition in Huntington's disease. Movement Disorders, 6, 127-132.

Mohr E, Claus JJ, Mann UM and Chase TN (1991b) In: Handbook of Clinical Trials: The Neurobehavioral Approach (Eds E Mohr and P Brouwers), pp. 243-274. Swets and Zeitlinger, Amsterdam.

Navia BA, Jordan BD and Price RW (1986) The AIDS dementia complex: I. Clinical features. Annals of Neurology, 19, 517-524.

Osborne D and Davis LJ (1978) Standard scores for Wechsler Memory Scale subtests. Journal of Clinical Psychology, 34, 115-116.

Perry EK (1986) The cholinergic hypothesis - ten years on. British Medical Bulletin, 42(1), 63-69.

Pillon B, Dubois B, Ploska A and Agid Y (1991) Severity and specificity of cognitive impairment in Alzheimer's, Huntington's, and Parkinson's diseases and progressive supranuclear palsy. Neurology, 41, 634-643.

Price RW, Brew B, Sidtis J, Rosenblum M, Scheck AC and Cleary P (1988) The brain in AIDS: central nervous system HIV-1 infection and AIDS dementia complex. Science, 239, 586-592.

Salmon DP, Kwo-on-Yuen PF, Heindel WC, Butters N and Thal LJ (1989) Differentiation of Alzheimer's disease and Huntington's disease with the Dementia Rating Scale. Archives of Neurology, 46, 1204-1208.

Sano M, Stern Y, Williams J, Cote L, Rosenstein R and Mayeux R (1989) Coexisting dementia and depression in 
Parkinson's disease. Archives of Neurology, 46, 12841286.

Taylor AE, Saint-Cyr JA and Lang AE (1986) Frontal lobe dysfunction in Parkinson's disease. Brain, 109, 845883.

Wechsler D (1981) Wechsler Adult Intelligence Scale-Revised. The Psychological Corporation, New York.
Wechsler D and Stone CP (1945) Wechsler Memory Scale. The Psychological Corporation, New York.

(Received 4 August 1994; accepted as revised 17 January 1995) 


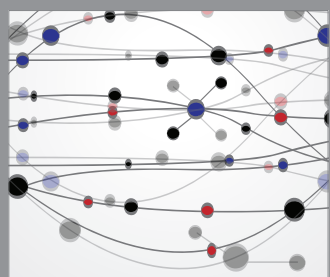

The Scientific World Journal
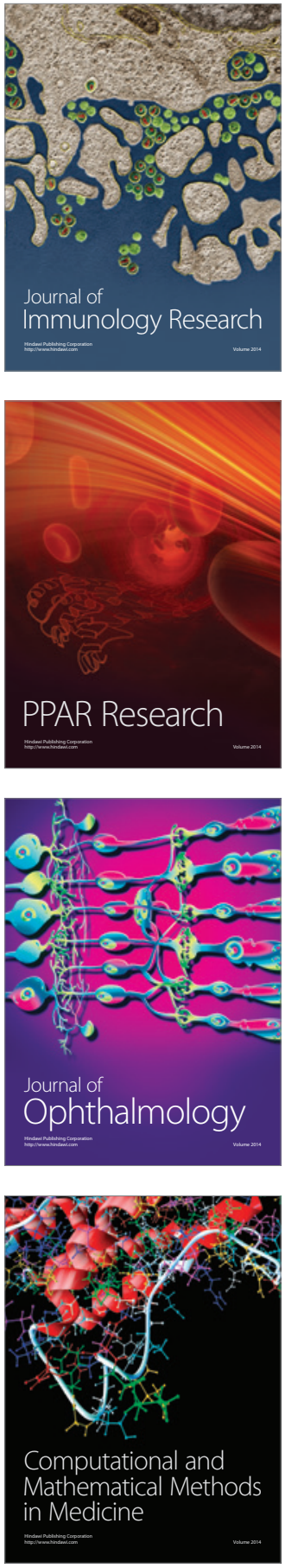

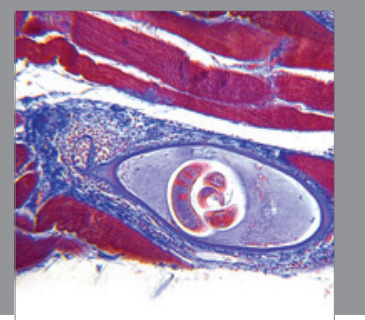

Gastroenterology

Research and Practice
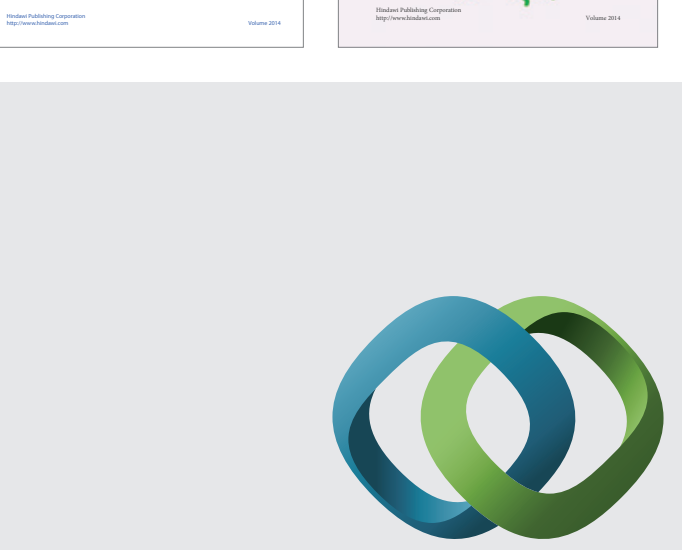

\section{Hindawi}

Submit your manuscripts at

http://www.hindawi.com
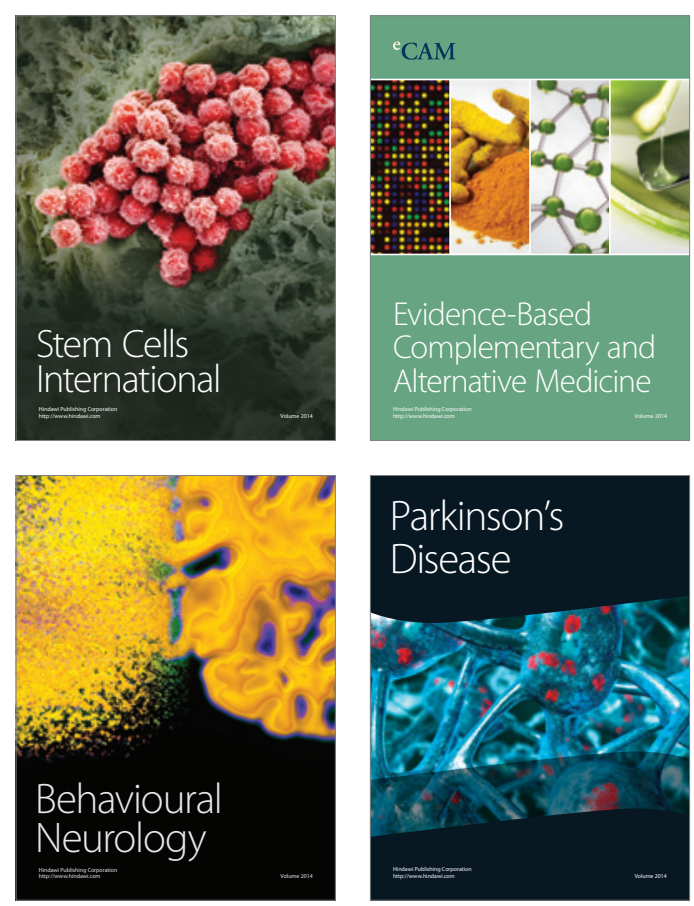

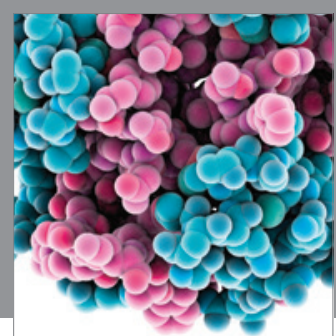

Journal of
Diabetes Research

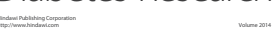

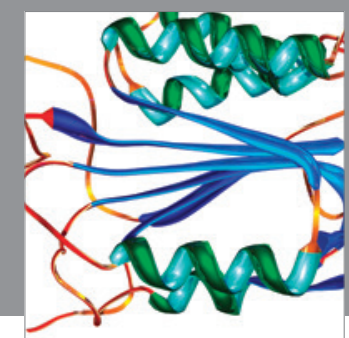

Disease Markers
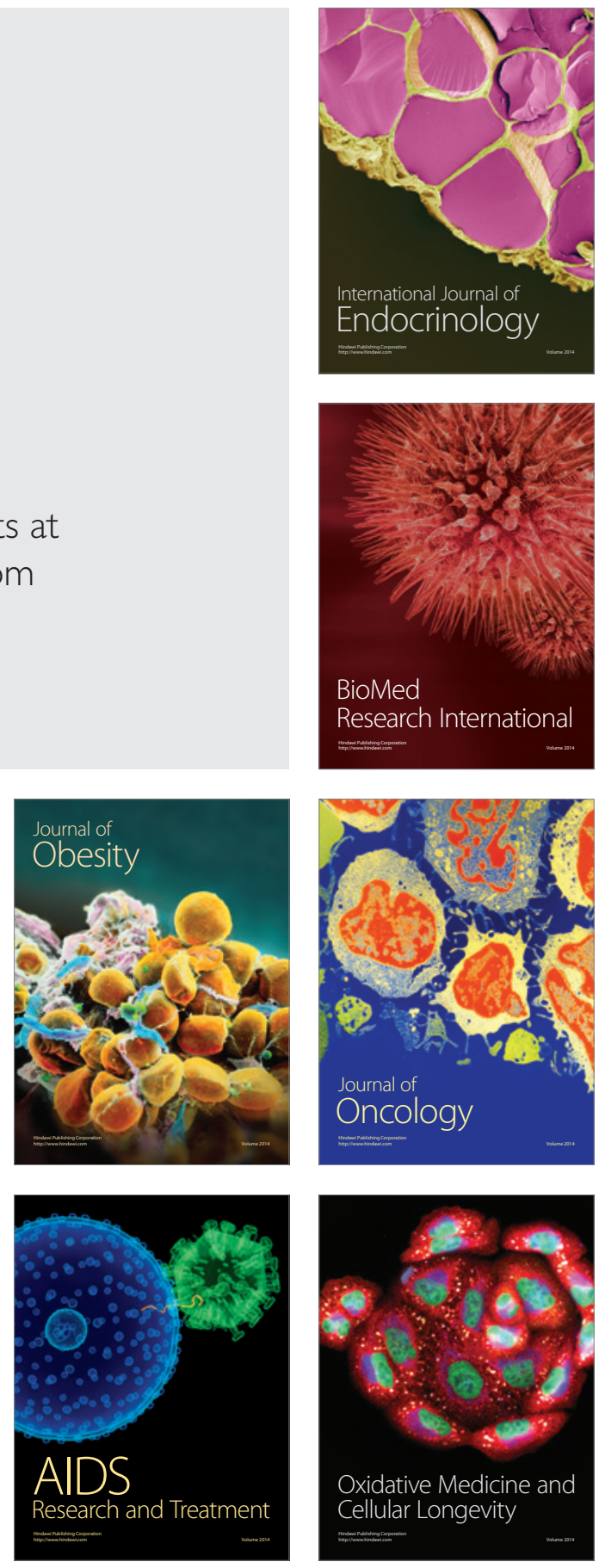